Article

\title{
Investigation on Mechanical Characteristics and Microstructure of Cemented Whole Tailings Backfill
}

\author{
Armelle Estelle Belibi Tana ${ }^{1,2, *}$, Shenghua Yin ${ }^{1,2}$ and Leiming Wang ${ }^{1,2, *(D)}$ \\ 1 School of Civil and Resource Engineering, University of Science and Technology Beijing, \\ Beijing 100083, China; yinshenghua@ustb.edu.cn or csuysh@126.com \\ 2 Key Laboratory of High-Efficient Mining and Safety of Metal Mines of Ministry of Education, \\ Beijing 100083, China \\ * Correspondence: b20160567@xs.ustb.edu.cn or armelle.belibi@gmail.com (A.E.B.T.); \\ ustb_wlm@126.com (L.W.)
}

Citation: Belibi Tana, A.E.; Yin, S.;

Wang, L. Investigation on Mechanical Characteristics and Microstructure of Cemented Whole Tailings Backfill.

Minerals 2021, 11, 592.

https://doi.org/10.3390/

$\min 11060592$

Academic Editor: Abbas Taheri

Received: 19 April 2021

Accepted: 24 May 2021

Published: 31 May 2021

Publisher's Note: MDPI stays neutral with regard to jurisdictional claims in published maps and institutional affiliations.

Copyright: (c) 2021 by the authors. Licensee MDPI, Basel, Switzerland. This article is an open access article distributed under the terms and conditions of the Creative Commons Attribution (CC BY) license (https:// creativecommons.org/licenses/by/ $4.0 /)$.

\begin{abstract}
A paste backfill performance can be primarily evaluated through the mechanical and physical characteristics of the components involved. In this study, the effects of solid components' tailings, binders and waters contents on microstructural evolution and mechanical properties of uncemented whole tailings backfill (CWTB) mixtures were investigated. Different mixtures of ordinary Portland cement of 1,3 and $5 \mathrm{wt}$. \% and solid concentrations at $72 \mathrm{wt} . \%, 74 \mathrm{wt} . \%$ and 75 wt. \% were selected and rheological test was conducted to define the slump fluidity and yield stress. The microstructure of the solid component before and after the preparation and chemical composition were analyzed by the Scanning electron microscope and XRD analysis, respectively. The results show that a positive correlation between yield stress and slump values of CWTB paste slurries, the decrease of flow consistence leads to the reduction of the water content on the CWTB mixtures and the flow resistance of the paste. With the highest solids content, unconfined compressive strength (UCS) of CWTB varies between $0.1-0.9 \mathrm{MPa}$. Increasing the solid content affects the porosity and improves the strength resistance of CWTB mixtures. The findings in this study can therefore lead us to a statement that CWTB chemical components seem to be an important factor in cemented paste backfill (CPB) design and mine operations.
\end{abstract}

Keywords: cemented whole tailings backfill; solids contents; mechanical characteristics; microstructure; cemented paste backfill

\section{Introduction}

In China, a total surface waste of 14.6 billion tons and about 1.28 billion $\mathrm{m}^{3}$ of goafs are left underground, which brings out serious environmental and security problems [1-3]. As perceived by some observers, 28 provinces, including districts and cities, are affected and show direct and side effects on the surrounding environment, allowing us to keep in mind that environmental protection and security of resources are national policy needs and concerns. Cemented paste backfill in China is undergoing significant development in the mining industry [4]. Cemented paste backfill has been considered a green technique, which can solve the subsidence of surface and underground mines to protect the environment and improve mining resource recovery $[1,5]$. As described in many studies, the cemented paste backfills are a type of mixed material composite made with a combination of crushed mineral tailings (70-85 wt. \% solids) from an ore plant extractive operation, mixed with water (fresh or mine processed water) and hydraulic binders (slag, Portland cement, fly ash, etc.) [6-8]. To obtain the required mechanical resistance properties of cemented backfill, the proportion of each component involved needs to be determined. As mentioned in other studies, the tailings ratio could be approximately between $80 \%-85 \%$, the water percentage ranges from $15 \%$ to $25 \%$ by solid weight, and the portion of the hydraulic binder added could range from 3 to 7 wt. \% in all mixtures $[9,10]$. 
The variation among those parameters associated with environmental condition such as curing age and temperature during preparation of the cemented paste backfill can affect the mechanical strength and stability of the overall paste backfill desired [7]. Generally, the physicochemical characteristic of the crushed mineral tailing, such as particle size, pore structure, moisture and the chosen cements (binders, superplasticizer and admixture flocculants) are the most influencing factors. Research studies conducted by Yin, et al. (2012) [6] on the effect of ultra-fine grained tailings on paste backfill performance suggest that well-graded tailings can optimize the microstructural and mechanical properties of cementitious paste back-fill [11-13]. Ouellet et al. [14] has recommended that the paste backfill should contain a minimum of $15 \%$ to $20 \%$ solids finer than $20 \mu \mathrm{m}$. Additionally, Benzaazoua, et al. [15] have provided some guidance to better control the hardening phenomena of paste backfills. Furthermore, Rheology and geomechanical stability reflect the quality and performance of the cemented paste backfill [16]. Rheology is explained in terms of slump, the solid content, shear yield strength and the uniaxial compressive strength [16-19].

To better understand this phenomenon and quality of the paste backfill, this study has been conducted by using various required percentages of solid concentration to prepare a cemented paste backfill. To achieve this, three solid contents and three binder dosages of ordinary Portland cement were used for investigating mechanical characteristics and microstructural of paste backfill. In addition, major factors, such as solid contents, binder dosages, water content and curing time, were mainly considered for slump tests, yield stress and unconfined compressive strength (UCS), and the relationship between those parameters with UCS of cemented whole tailings backfill (CWTB) samples were studied. Further, the scanning electron microscopy (SEM) technique was used to evaluate at 14, 28 and 42 days the cured CWTB samples containing $1 \mathrm{wt}$. \% binder dosage with different solid contents. We expected that the results of this research study will provide good knowledge on the rheological properties of the required CWTB, which will give an efficient performance on the behavior of the above-mentioned material, under comparable situations.

\section{Materials and Methods}

\subsection{Tailings, Binder Characteristics and Water}

2.1.1. Tailings Characteristics Based on Elements Collected through Jinchuan Nickel Mine Site

The tailings materials used in this study were sulfides-rich tailings. These wet tailings samples were the underflow of overburden thickener in the concentrator, taken from the tailings treatment plant of Jinchuan nickel mine deposit located in the Northwest area of Gansu province, (China). These raw tailings were kept wet and transported to the laboratory in sealed plastic bags to prevent oxidation and/or evaporation. Before the experimental analysis, the mills tailings were placed in a drying box furnace and naturally cooled to prepare the paste tailings samples. Particle size distribution (PSD) of the tailings specimens was determined (Figure 1) using the size analysis and determination of soil constants procedure (ASTM D421) [20] and Malvern top sizer laser particle size analyzer (Shanghai, China) [21]. Many paste tailings were used wet in order to conduct a set of experimental tests needed for material characterization. The tailings samples were determined to contain $12 \%$ sulfur (S), and the analysis confirms the presence of pyrite in mineral wastes. 


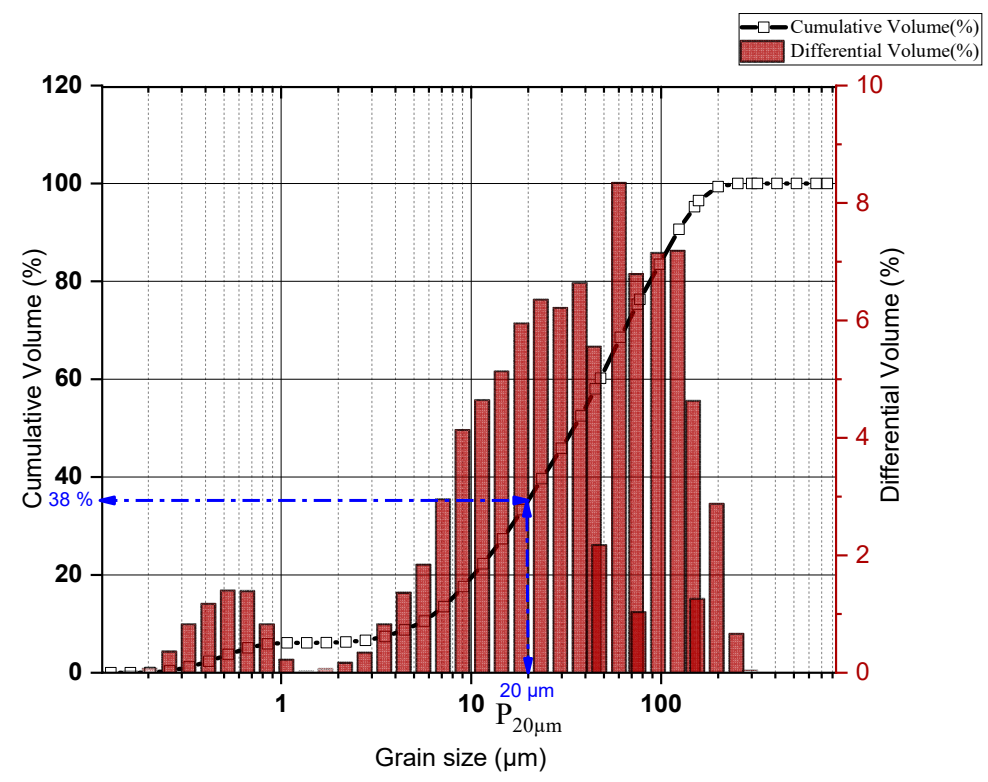

Figure 1. Particle size distribution of tailings.

The results of the physical characterization of the tailings presented in Table 1 and Figure 1 illustrated that the tailings material used has an apparent porosity around 36\%, a specific gravity of 2.8 , a bulk density of $2.3 \mathrm{~g} / \mathrm{cm}^{3}$ and a specific surface area (SSA) of $630.036 \mathrm{~m}^{2} / \mathrm{kg}$. The measurements cover a range of 0.1 to $750 \mu \mathrm{m}$ with $1 \%$ precision. It was observed that the contents of $0.075 \mathrm{~mm}$ and $0.025 \mathrm{~mm}$ in the tailings account, respectively, for $83.18 \%$ and $36 \%$. Still, the content of $0.038 \mathrm{~mm}$ particles accounts for $64.24 \%$, and that of $0.02 \mathrm{~mm}$ particles accounts for $47.03 \%$, as demonstrated by Yin et al. [6] on the particle size of fine sandy aggregates. The obtained GSD based on the ASTM standard [22] shows the tailings sample is well-graded sand with a coefficient curvature Cc (Equation (1)) and a coefficient of uniformity $\mathrm{Cu}$ (Equation (2))

$$
c_{c}=\frac{D_{30}^{2}}{D_{60} * D_{10}}
$$

(Cc) expressed the coefficient of curvature, which is the grading ratio of square $D_{30}$ to $D_{60}$ and $D_{10} . D_{10}, D_{30}$ and $D_{60}$ are effective particle size with $10 \%, 30 \%$ and $60 \%$ of finer particles in the total soil, respectively. The calculated Cc was 1.3.

$$
c_{u}=\frac{D_{60}}{D_{10}}
$$

(Cu) expressed the particle size ratio of $D_{60}$ to $D_{10} . D_{10}$ and $D_{60}$ are respectively effective particle size with $10 \%$ and $60 \%$ of finer particles in the total soil. The calculated $\mathrm{Cu}$ was 8.5 and is summarized in Table 1.

Table 1. Physical characteristics of tailings and ordinary Portland cement.

\begin{tabular}{cccccccccccc}
\hline Compounds & $\begin{array}{c}\mathbf{D}_{\mathbf{9 0}} \\
(\mu \mathrm{m})\end{array}$ & $\begin{array}{c}\mathbf{D}_{\mathbf{6 0}} \\
(\mu \mathrm{m})\end{array}$ & $\begin{array}{c}\mathbf{D}_{\mathbf{5 0}} \\
(\mu \mathrm{m})\end{array}$ & $\begin{array}{c}\mathbf{D}_{\mathbf{3 0}} \\
(\mu \mathrm{m})\end{array}$ & $\begin{array}{c}\mathbf{D}_{\mathbf{1 0}} \\
(\mu \mathrm{m})\end{array}$ & $\begin{array}{c}\mathrm{Cu} \\
(-)\end{array}$ & $\begin{array}{c}\mathrm{Cc} \\
(-)\end{array}$ & $\begin{array}{c}\text { SSA } \\
\left(\mathbf{m}^{\mathbf{2}} / \mathbf{k g}\right)\end{array}$ & $\begin{array}{c}\text { Porosity } \\
(\mathbf{\%})\end{array}$ & $\begin{array}{c}\text { Bulk } \\
\mathbf{D e n s i t y} \\
\left(\mathbf{k g} / \mathbf{m}^{\mathbf{3}}\right)\end{array}$ & $\begin{array}{c}\mathrm{Gs} \\
(-)\end{array}$ \\
\hline Tailings & 121.78 & 58.33 & 44.887 & 22.73 & 6.83 & 8.54 & 1.30 & 630.04 & 36 & 2.3 & 3.4 \\
OPC & 44.59 & 21.71 & 17.057 & 9.35 & 0.73 & 29.79 & 5.53 & 2067.94 & - & - & 2.8 \\
\hline
\end{tabular}

As the results showed, the tailings could be respectively classified as silty sand tailings. The chemical composition of the waste made through X-ray fluorescence analysis allowed the list of the results presented in Table 2. As displayed in Table 2, the dominant chemical 
elements are silicon dioxide (42.2\%), magnesium oxide (32.7\%) and ferric oxide (12.14\%), aluminum oxide $(4.04 \%)$, calcium oxide $(3.73 \%)$ with lower amounts of potassium oxide $(0.39 \%)$ titanium dioxide $(0.33 \%)$, sulfur $(1.25 \%)$, copper $(0.26 \%)$, chlorite $(0.057 \%)$ and nickel $(0.28 \%)$, same compositions of sulfur and nickel are conferred to [11,12] Looking at the loss-on-ignition, it was apparent that organic substances and volatile compounds made up about $4.22 \%$ of the tailings. The mineralogical composition obtained using A Ultima IV X-ray diffractometer equipped with a copper anticathode (Rigaku, Tokyo, Japan), X-ray analyses specified in Figure 2a that the abundant silicate minerals are quartz, Lizardite (serpentine mineral) and Alite comprised the natural sand, accompanied by lesser amounts of other minerals such as Clinochlore (chlorite mineral), Magnetite (Spinel ferrites), halite and sylvite. The diffraction peaks at $2 \theta=12.1^{\circ}, 24^{\circ}$ and $39.19^{\circ}$ are the typical of (001), (002) and (220) planes of Lizardite $(\mathrm{Mg}, \mathrm{Al})_{3}(\mathrm{Si}, \mathrm{Fe})_{2} \mathrm{O}_{5}(\mathrm{OH})_{14}$ crystal phase (JCPDS 50-1625). Additionally, the XRD patterns diffraction also revealed at $2 \theta=24.097^{\circ}$ and $44.9^{\circ}$ correspond to (112) and (204) planes of Clinochlore crystal phase (JCPDS 79-0761). The diffraction peaks at $2 \theta$ values of $11.58^{\circ}$ and $28.10^{\circ}$ are the reflections of $(020)$ and (111) planes of Gypsum crystal phase (JCPDS 33-0311). The diffraction peaks at $2 \theta$ values of $35.42^{\circ}, 56.94^{\circ}$ and $70.924^{\circ}$ were indexed to the of (311), (511) and (620) planes of Magnetite crystal phase (JCPDS 19-0629).

Table 2. Chemical characteristics of tailings and ordinary Portland cement.

\begin{tabular}{|c|c|c|c|c|c|c|c|c|c|c|c|c|c|}
\hline Compounds (\%) & $\mathrm{SiO}_{2}$ & $\mathrm{CaO}$ & $\mathrm{Fe}_{2} \mathrm{O}_{3}$ & $\mathrm{M}_{\mathrm{g}} \mathrm{O}$ & $\mathrm{Al}_{2} \mathrm{O}_{3}$ & $\mathbf{S}$ & $\mathrm{Ni}$ & $\mathrm{CuO}$ & $\mathrm{Cl}$ & $\mathrm{SO}_{3}$ & $\mathrm{TiO}_{2}$ & $\mathrm{~K}_{2} \mathrm{O}$ & Others \\
\hline Tailings & 42.2 & 3.73 & 12.14 & 32.71 & 4.04 & -1.25 & 0.28 & 0.26 & 0.057 & 3.37 & 0.33 & 0.39 & 4.22 \\
\hline OPC & 23 & 65.10 & 3.30 & 3.4 & 5.18 & -2.5 & & & 0.02 & 2.46 & 0.16 & 0.48 & \\
\hline
\end{tabular}
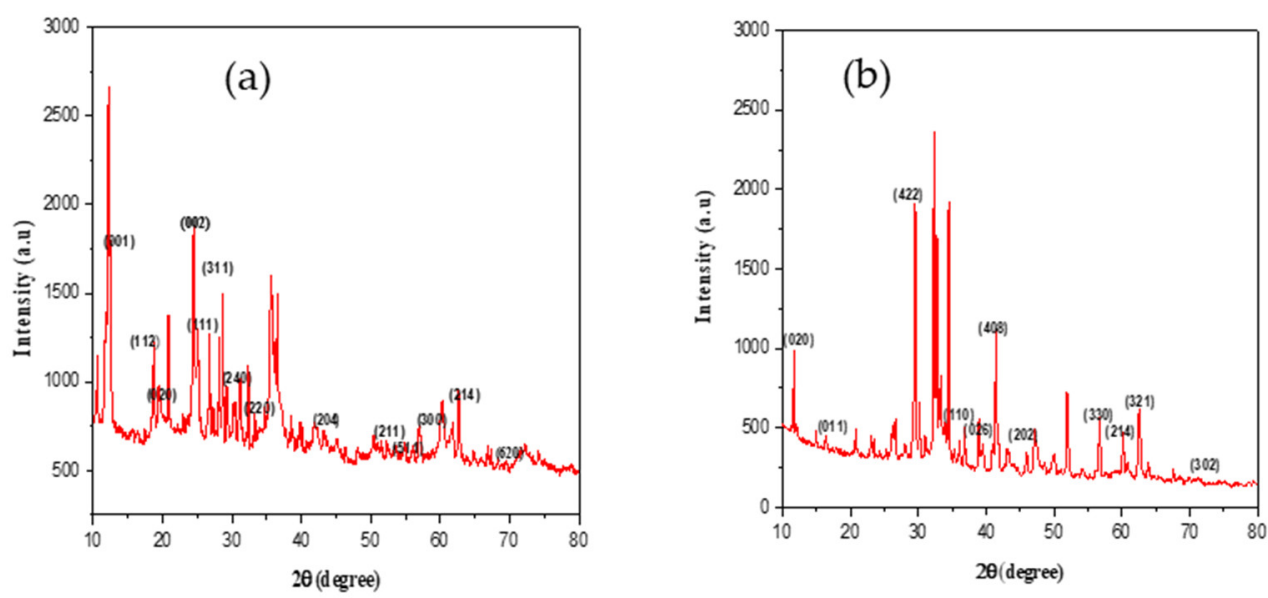

Figure 2. XRD patterns of tailings (a) and ordinary Portland cement (b).

\subsubsection{Binder Characteristics and Water}

The particle size distribution and the physical properties (density, specific surface area, etc.) of the binders are shown in Figure 1 and Table 1, respectively. The specific density $\left(2.92 \mathrm{~g} / \mathrm{cm}^{3}\right)$ and the specific surface area $\left(2067.94 \mathrm{~m}^{2} / \mathrm{kg}\right)$ of OPC are typical of cementitious materials. Besides, it was observed that the finer particles of ordinary Portland cement (OPC) shown in Table 1 are poor and unrecorded; it implies that OPC particles were poorly graded. Furthermore, the coefficient of uniformity of OPC shows uneven particle gradation. According to the Chinese standard (GB 175-2007), ordinary Portland cement used as a binder for this study is silica cement [23]. X-ray fluorescence (XRF) carried out to analyze the principal chemical constituents are presented in Table 2 . In the components of OPC (32.5R) [7], the main chemical was $\mathrm{CaO}(65.10 \%), \mathrm{SiO}_{2}(23 \%)$ and $\mathrm{Al}_{2} \mathrm{O}_{3}(5.18 \%)$ and a small amount of $\mathrm{K}_{2} \mathrm{O}, \mathrm{MgO}$. As shown in Figure 2b, mineralogical analysis of XRD diffraction patterns of ordinary Portland cement presents evidence of crystallized phases 
sufficiently soluble to take part in hydration. As we can see, the diffraction peaks found at $2 \theta=23.13^{\circ}, 43.2^{\circ}$ and $60.74^{\circ}$ corresponded to (012), (202) and (214) planes of calcite crystal phase (JCPDS 86-0174). The diffraction peaks appearing at $2 \theta$ values of $11.63^{\circ}, 16.50^{\circ}$ and $56.8^{\circ}, 38.92^{\circ}$ and $41.38^{\circ}$ were indexed to (020), (011), (321); (422), (026) and (408) planes of Gypsum and Tricalcium silicate (Hartrurite) crystal phases, respectively (JCPDS 70-0982 and 85-1378). Tap water was used to homogenize all the components included in CWTB mixture formulation.

\subsection{Experimental Methods}

Wet tailing samples were directly collected from the total tailing pump station, which were slurry and sealed in plastic barrels. A consolidation test is carried out to explore the strength of the tailings under the condition of different ratio of consolidation agent to find the appropriate consolidation agent and ratio. The proportion and the mixing elements used are presented in Table 3. The experimental technical route of cemented whole tailings backfill recipes are presented scheme in Figure 3. As displayed, the main steps of the CWTB's preparation begin, with choosing material to each process which include mixing of all CWTB recipes, slump test, pouring the CWTB's samples on triplicate square molds, curing box, servo compression testing machine for the unconfined strength compressive and scanning electronic microscopic for microstructure analysis of CWTB's samples.

Table 3. CWTB mixtures recipes at different solids and binder contents.

\begin{tabular}{ccccc}
\hline Sample $\mathbf{N}^{\circ}$ & Cw (wt. \%) & Tailings (g) & Water (mL) & Bw (wt. \%) \\
\hline 1 & 75 & 2500 & 844.59 & 1 \\
2 & 74 & 2500 & 890.41 & 1 \\
3 & 72 & 2500 & 985.92 & 1 \\
4 & 75 & 2500 & 868.06 & 3 \\
5 & 74 & 2500 & 915.49 & 3 \\
6 & 72 & 2500 & 1014.49 & 3 \\
7 & 75 & 2500 & 892.86 & 5 \\
8 & 74 & 2500 & 942.03 & 5 \\
9 & 72 & 2500 & 1044.78 & 5 \\
\hline
\end{tabular}
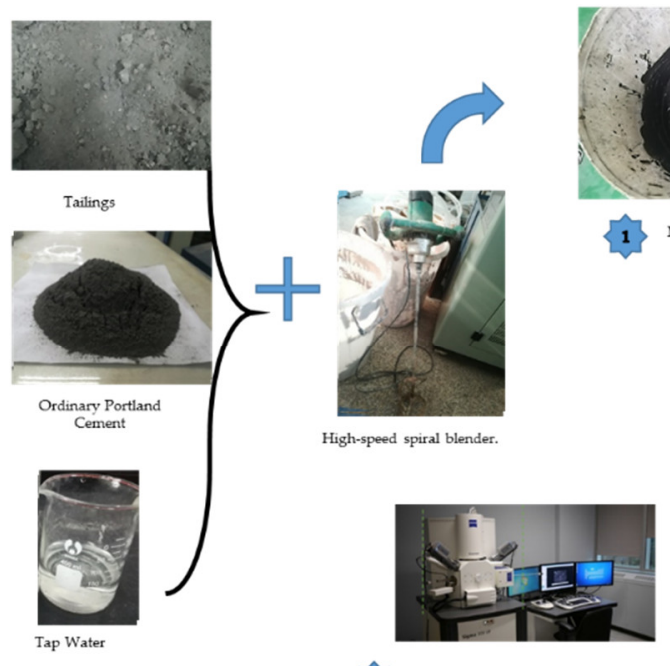

Scanning electron microscope

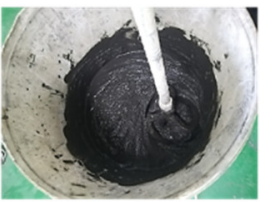

1 Mixing of all CWTB

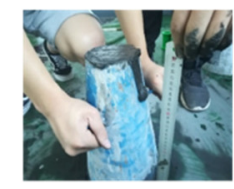

Slump Test

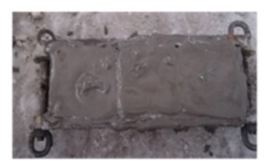

Triplicate

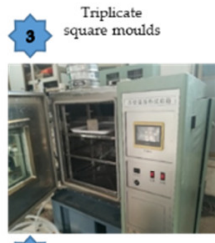

Curing Box

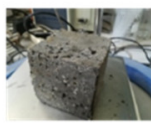

WTCB Specimen

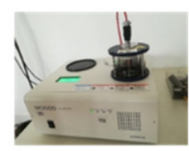

MC1000 Ion Sputter Coater

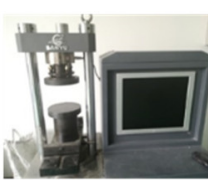

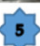

Figure 3. Experimental technical route of CWTB preparations. 


\subsubsection{Slump Test Preparation}

According to Clayton [24], a paste's rheological behavior properties can be estimated with a slump test. The slump technique is convenient to evaluate the flow properties of a different paste. In this study, the experimental slump procedure was made following the American standard test method (ASTM) C143/C143M-17 [25]. The effect of solids content, tailings and low binder content on CWTB performance were studied. A total of 9 paste backfills samples were prepared by mixing the tailings, tap water and binder with an immersion mixer at a selected homogeneous consistency. Each paste backfill was tamped 25 times with an iron rod to remove most of the sample's air pockets [26]. Depending on the different chosen concentrations of solids, the CWTB contained 79-85 wt. \% residues by a dry mass of the total mixes. Initial porosity contents for all whole tailings was set at $36 \%$. Water-cement $(\mathrm{w} / \mathrm{c})$ ratios of $26,8.3$ and 5 corresponded to binder proportions of 1,3 and $5 \mathrm{wt}$. \%, respectively. As an empirical measure of consistency, the slump height depends on both the density of the material and the plastic yield strength, which in turn depends on the particle size, specific gravity, size and chemical composition. To achieve the height of the slump desired, Equation (3) below has been used:

$$
\tau_{0}=\frac{225 \rho g V^{2}}{128 \pi^{2} R^{5}}
$$

where $\tau_{0}$ is plastic yield stress of paste, $\rho$ : density of paste material, $V$ : volume of water of paste tailings. $R$ : Radius of paste material, $g$ is the conventional gravitational acceleration due to the gravity of material expresses by standard formula $9.80 \mathrm{~m} / \mathrm{s}^{2}$.

Following Equation (4), the slump consistency was determined in Equation (4).

$$
S=25.5-17.6 \frac{\tau_{0}}{\rho}
$$

The paste material tested using the Abram cone reached 10,9 and 7 inches for different solids concentrations. Immediately after the slump test, the samples were mixed again once and then poured into molds of the same size $(7.05 \times 7.05 \times 7.05 \mathrm{~cm})$ and the resulting CWTB specimens were left at ambient room temperature for five days, to remove the excess of water.

According to Equations (3) and (4), the plastic yield stress $\left(\tau_{0}\right)$ and slump heights of CWTBs samples at different solids content were calculated and the values are reported in Table 4.

Table 4. Slump height of CWTB at different solids contents.

\begin{tabular}{ccccc}
\hline Cw (wt. \%) & $\left.\rho \mathbf{~} \mathbf{k g} / \mathbf{m}^{\mathbf{2}}\right)$ & $\boldsymbol{R}$ (cm) & $\boldsymbol{\tau}_{0} \mathbf{( P a )}$ & $S$ (cm) \\
\hline 75 & 2960.0 & 0.085 & 72,848 & 19,118 \\
74 & 2807.7 & 0.107 & 23,644 & 25,702 \\
72 & 2535.7 & 0.11 & 21,567 & 23,333 \\
\hline
\end{tabular}

The resulting paste backfill squares were then stored and cured in a controlled humidity chamber with $95 \%$ relative humidity and a temperature of $27^{\circ} \mathrm{C}$ during the desired curing times of 14, 28 and 42 days [26] to simulate typical curing conditions in operation mines [27].

\subsubsection{Unconfined Strength Test}

Unconfined compression tests are frequently used for cemented soils and concrete, and much experience regarding them has been reported. Additionally, the unconfined compression strength (UCS) is the main strength index used to evaluate CWTB's strength performance [28]. According to ASTM C39/C39M [29], the UCS and the total porosity of CWTB samples were determined. For this study, a Servo compression testing machine with a single axis press made by Sanyu was used. The range of the press is $0 \sim 50 \mathrm{kN}$. The 
loading speed and size of the test block were adjusted by the support of a software. The loading speed was set at $0.1 \mathrm{kN} / \mathrm{s}$. The height, length and width of the test block manually entered into the single axis press computer is $7.07 \mathrm{~cm}$, and for each group a number of 3 blocks were tested. For accuracy, each curing time test was carried out in triplicate, and only the maximum average strength was considered [5]. The porosity test was performed for each mass concentration at different binder proportions.

To predict the mechanical strength of CWTB, the formula (Equation (5)) held to:

$$
U c s=\kappa\left(\frac{B_{w}}{B_{w}+v_{w}+e}\right)^{2}
$$

where $K$ is the constant, $B w$ is the cement ratio; $V_{w}$, the water content of each CWTB recipe and $e$ is the void ratio of CWTB sample ad different curing time.

\subsubsection{Microstructural Test}

The microstructure of CWTB's was examined under a ZEISS EVO 18 (SEM, Jena, Germany) scanner electron microscope. Before carrying out the SEM analysis, the samples were dried 3 times with the MC1000 Ion Sputter Coater at $50{ }^{\circ} \mathrm{C}$, until they reached good stability for microscopic observation. This makes it easier to cover smaller diameter particles at a high granularity and to minimize damage to the sample irradiation for rapidly moving.

\section{Results and Discussions}

3.1. Influence of the Solids Content on the on the Slump Values of Cemented Whole Tailings Backfill

Figure 4 illustrates the variation in slump heights for CWTB mixtures prepared at CW of 72 wt. $\%, 74$ wt. $\%$ and 75 wt. \% and BW of 1 wt. \% OPC binder by weight. The slump heights were decreased with the increase of the solids' contents.

Different solid content concentration was selected to evaluate the mechanical strength and quality of cemented paste backfill under laboratory condition. The variable solid percentage was set at 72, 74 and $75 \mathrm{wt}$. \% and bind with OPC at $1 \mathrm{wt}$. \%. The result from slump test showed that the increased in solid content result in the decrease of the slump values. This value was noted to decrease from $25 \mathrm{~cm}$ for the solid content of $72 \%$, to $19.1 \mathrm{~cm}$ for the solid content of 75\% (Figure 5). According to Ouattara et al., 2018, CPB can be easily transported by gravity when the slump values range from $21 \mathrm{~cm}\left(8 \frac{1}{2}\right.$ inches $)$ to $25.4 \mathrm{~cm}$ (10 inches) [30]. After that the slump value rapidly reduces, showing the hydration of cement. [31,32]. This experiment suggests that OPC binder and water contents of CWTB samples speed up cement's hydration process.

Further, higher mass fraction of tailings leads to the consistency of slump desired. Figure 5 confirmed Figure 4 with the reduction of slumps' heights whilst the solids content increased. This is due to the fact that the strength of particles at different solids content increased with the ratio of tailings, which reduced water and then enhanced the compaction of the paste and characterized the filling of void ration included on the tailings.

The relationship between slump values and yield stress of CWTB's mixtures at $1 \mathrm{wt}$. \% OPC was discussed in Figure 6. It showed that the variation of fluidity of CWTB's mixtures set up higher yield stress with the increase of mass concentration. It is due to the reduction in water content resulting in a decrease in porosity caused by the reduction in the void ratio between particles, which results in colloidal interaction between particles caused by the hydration products used. In addition, free water migration is reduced between paste particles, optimizing the slump fluidity and improving the yield strength of different CWTB mixtures at different mass concentrations. Thus, by binding the hydration of the OPCs and particles in direct contact, this network structure increases the lubricating film thickness and improves the yield stress of the CWTB mixtures $[4,33]$. 

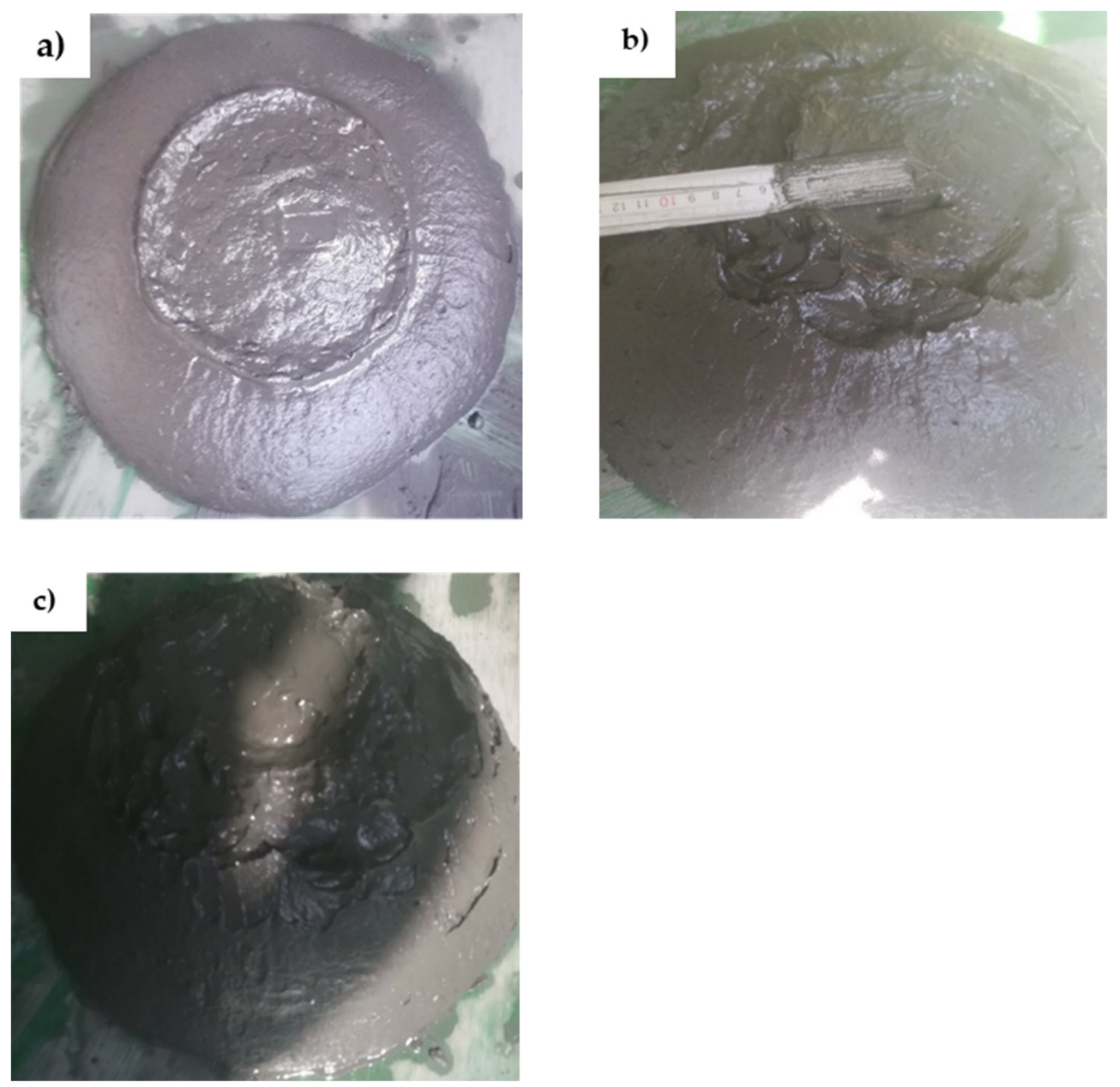

Figure 4. Slump consistency of CWTB at (a) 72 wt. \%, (b) 74 wt. \%, (c) 75 wt. \% with 1 wt. \% of binder dosage.

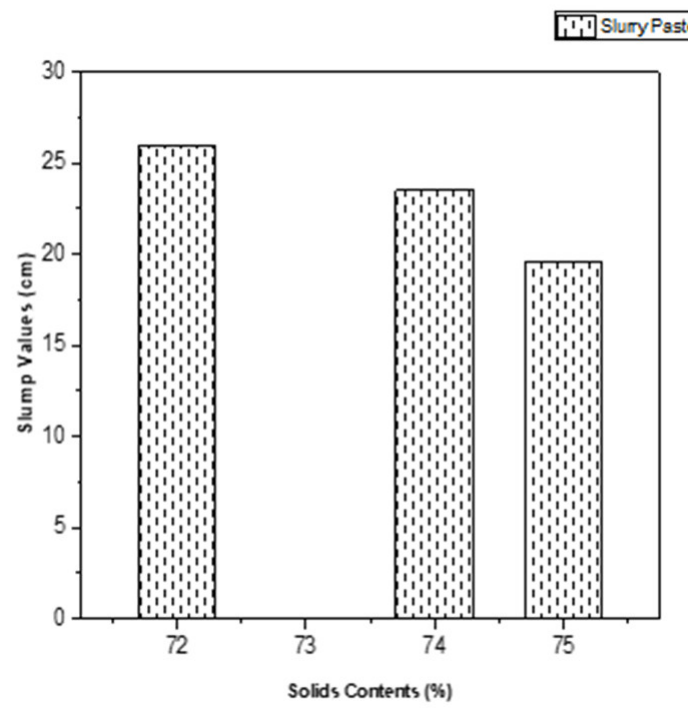

Figure 5. Slump values for different CTB at $\mathrm{Cw} 72$ wt. \%, 74 wt. $\%$ and 75 wt. $\%$ and binder of 1 wt. \%. 


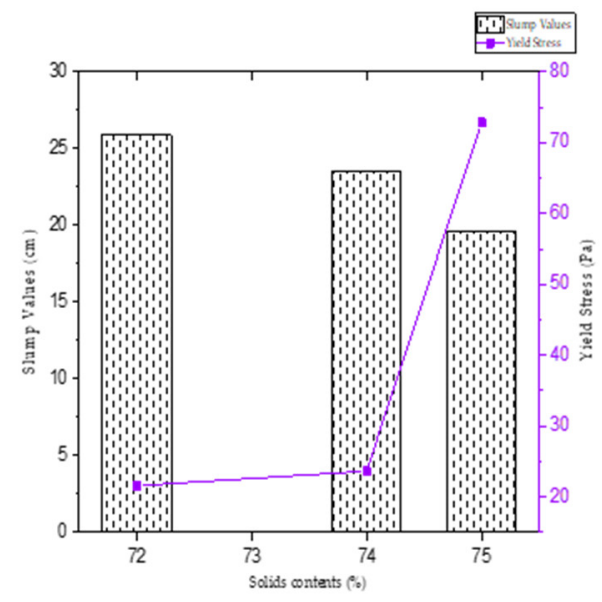

Figure 6. Relationship between yield stress and slump values for different CTB at Cw 72 wt. \%, 74 wt. $\%$ and 75 wt. $\%$ and binder of 1 wt. $\%$.

\subsection{Effect of Solid Content on the Microstructural Properties of CWTB}

Figure 7 shows scanning electron microscope (SEM) images of different binder dosages 1,3 and $5 \mathrm{wt}$. $\%$ at a solid content of $75 \mathrm{wt}$. \%. The tailings had a rough and uneven surface, while the natural sand had a smoother surface [34]. Indeed, the percentage of ordinary Portland cement has increased in the formulation of paste backfill mixtures. There is an increase in the mechanical strength of CWTB samples due to the activation of secondary C-S-H gels such as ettringite, $\mathrm{C}_{3} \mathrm{~S}$ gypsum contained in ordinary Portland cement. Besides, adding Portland cement is very effective in reducing metal mobility. The hydration age of 14 days at $75 \mathrm{wt}$. \% solids content with $5 \mathrm{wt}$ \% binder dosage is presented in Figure 7a,b. From these figures, we have the confirmation of the increase in hydration products reveals by the X-ray diffraction test. The increased dose of OPC allows direct particle-to-particle contact, which improves the microstructure of CWTB samples and leads to $\mathrm{CSH}$ gel, ettringite and gypsum formation. So, the use of OPC binder leads to a reduced permeability of the paste at solids content of $75 \mathrm{wt}$. \%. In Figure $7 \mathrm{c}, \mathrm{d}$, after the hydration age of 28 days at $75 \mathrm{wt}$. \% solids content with $3 \mathrm{wt}$. \% binder dosage, there are a glassy phase and some lower hydration products that bond to the cemented particles. We can observe the tailings, quartz and some lower presence of voids.

However, Figure 7e,f shows that after hydration age of 42 days at $75 \mathrm{wt}$. \% solids content with $1 \mathrm{wt}$. \% of binder dosage, there is a high porosity (presence of voids) and insufficient quantity of hydration products to bond to the cemented. Note that X-ray diffraction (XRD) analyses performed on the weathered zone did not show any secondary minerals. This was unexpected, as secondary minerals are often poorly crystallized or amorphous and therefore ignored by the XRD analysis [35]. Moreover, the quantity of secondary minerals could often be under the detection limit of the XRD analysis.

From the SEM image, it can be seen that with the increase of the slurry concentration, the porosity of the paste at 14, 28 and 42 days of curing decreases, which is due to the hydration products gradually covering the original pores, and the decrease of porosity. The paste at 28 days of curing at four concentrations rarely saw a single calcium acicular stone and C-S-H column, which is due to the continuous development of hydration products. The results show that the porosity of CWTB decreases with increasing curing time [17,31].

The results show that when the concentration of the slurry is $75 \mathrm{wt}$. \%, with the increase of curing time at different times, the hydration reaction is gradually carried out, and the hydration products gradually fill the pores, which makes the strength of the paste backfill gradually increase [18]. 

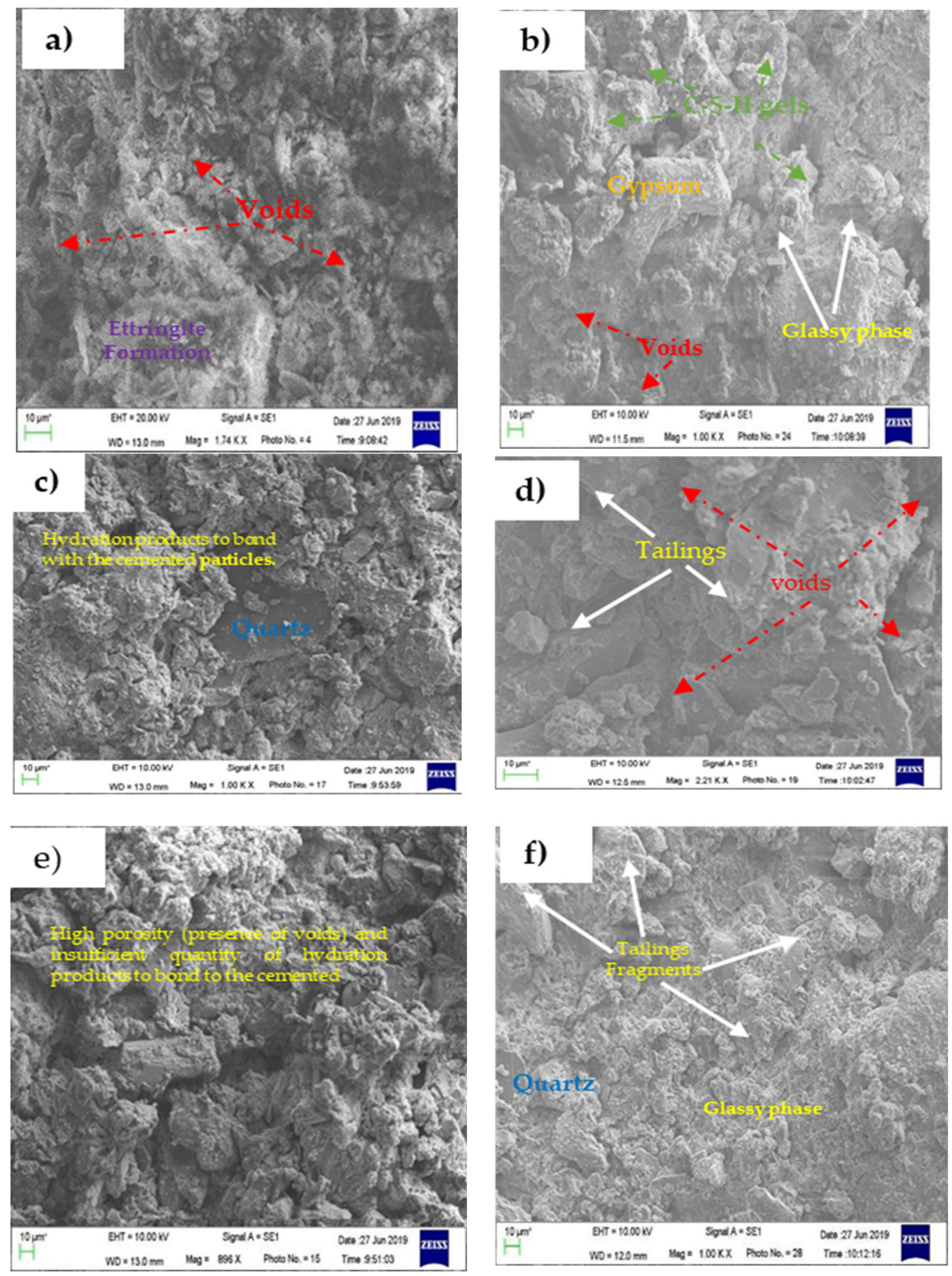

Figure 7. Microstructure properties of CWTB at solids content $75 \mathrm{wt}$ \% $\%$ as a function of curing time $(\mathbf{a}, \mathbf{b}) 14,(\mathbf{c}, \mathbf{d}) 28$ and $(\mathbf{e}, \mathbf{f}) 42$ days at different binders' dosage.

However, the compounds of CWTB mixtures hinder the hydration reaction of cement, there are large pores in the 42 days of curing, and the existence of large pores is the main reason for the low strength of the paste backfill. In SEM images, the pore size of $75 \mathrm{wt}$. $\%$ concentration was the smallest, and the porosity was also the smallest. Although the pore size of $74 \mathrm{wt}$. \% concentration was larger than that of $72 \mathrm{wt}$. \% concentration group, the porosity was smaller than that of $74 \mathrm{wt}$. \% concentration group and the pore size and porosity of $72 \mathrm{wt}$. \% concentration was the largest. This also verifies the previous test results of porosity and explains the reason why the strength changes with the concentration from the perspective of porosity and hydration products $[4,28,35]$ 
For better optimization of CWTB's microstructures, another SEM-EDS analysis was carried out with a Brunker JEOL JSM 7610F used for its high performance. Figure 8 displays the microstructures at $10 \mu \mathrm{m}$ and $1 \mu \mathrm{m}$. SEM micrograph of the CWTB samples containing different binder dosages at $75 \mathrm{wt}$. \% solids contents was analyzed after the testing of UCS. It was observed that the voids between the matrix of CTWB's samples reduced from those in Figure 8a-d [19]. In addition, the chemical composition revealed by the EDS graph (Figure 8e) shows the persistence of the calcium element, followed by the sulfate element. This finding is in accordance with the initial composition of the tailings before CWTB mixtures [36,37].
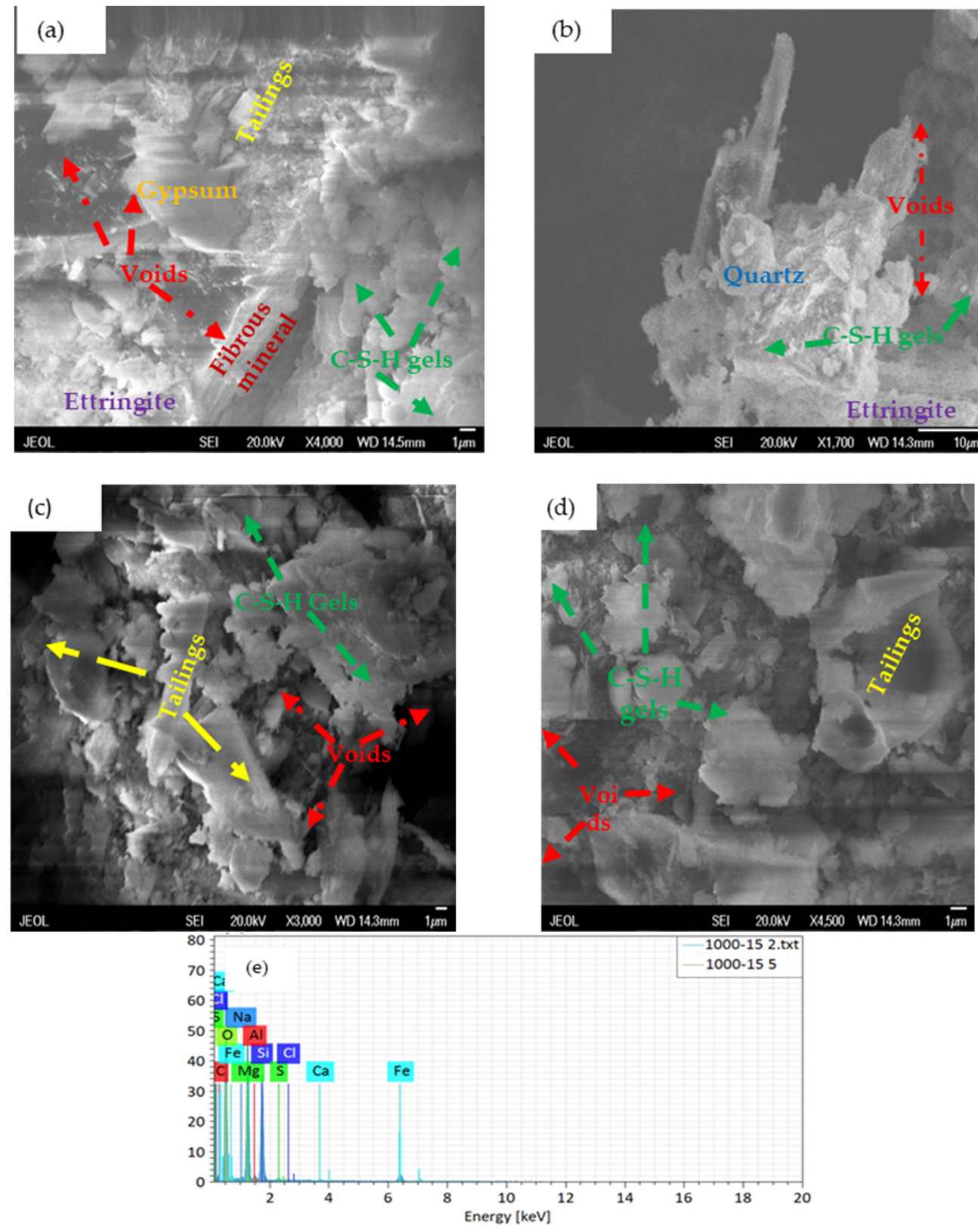

(b)

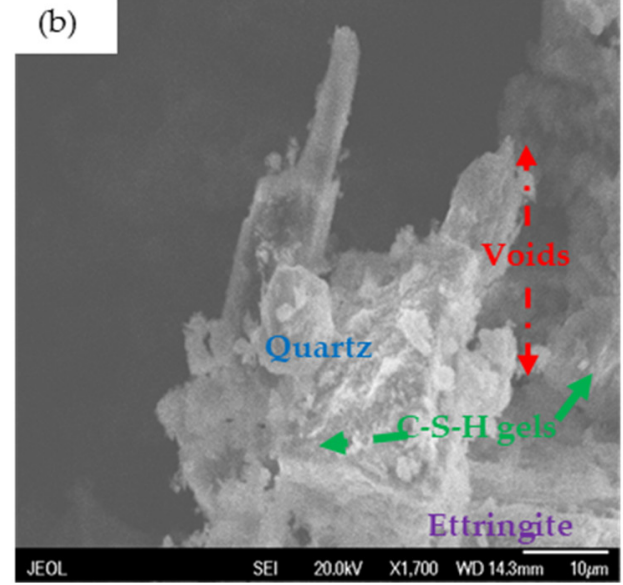

(d)

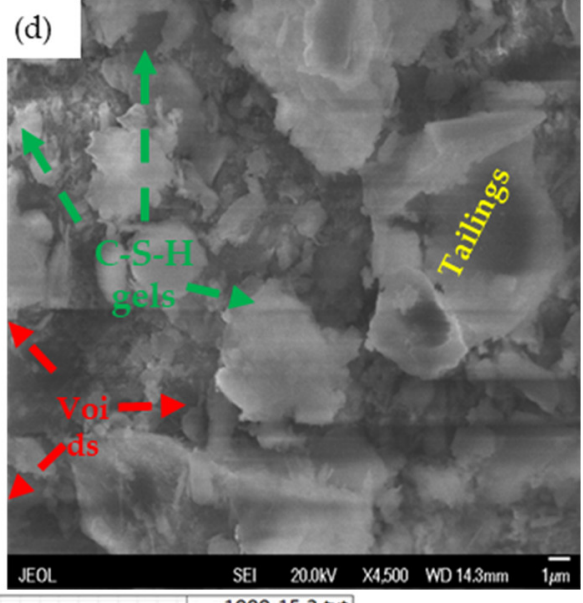

Figure 8. SEM-EDS microstructural evolution of CWTB at solids content $75 \mathrm{wt}$ \% as a function of curing time (a) 14, (b) 28 and (c,d) 42 days at different binders' dosage and (e) EDS spectrum of multi-elements.

\subsection{Influence of the Solids Content on the Mechanical Strength of Fresh Cementitious Materials}

The unconfined compressive strength (UCS) and the total porosity of CWTB samples were determined, according to ASTM C39 [7]. Figure 9 shows that CWTB with higher 
solids content presented higher UCS values for each curing time, and with lower solids content-lower UCS values for each curing time; UCS increased with curing time for each CWTB formulation. For example, at 28 days of curing, CWTB at Cw of $72 \mathrm{wt}$. \% and $74 \mathrm{wt}$. \% showed the same UCS of $0.2 \mathrm{MPa}$, but at $\mathrm{Cw}$ of $72 \mathrm{wt}$. \% of 28 days curing, there is a relative increase of UCS value corresponding to $0.9 \mathrm{MPa}$. Similar results of UCS values increase with the rise CWTB Cw concentrations from $74 \%$ to $80 \%$ and $75 \%$ to $80 \%$ were found by Yin et al., 2012 and Ouattara et al. 2018, respectively [6,30].

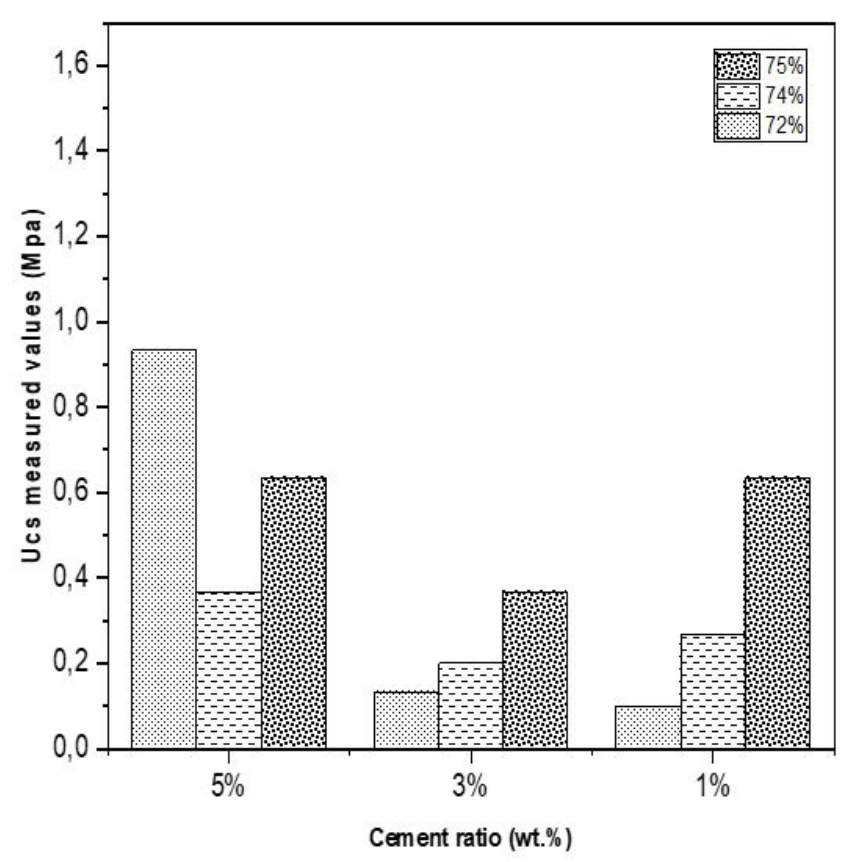

Figure 9. Effects of the solids content of CWTB mixtures prepared with 1 wt. \%, 3 wt. \% and 5 wt. \% OPC binder on the variation in unconfined compressive strength with cement ratio.

The paste sample with an initial solid concentration of $72 \mathrm{wt}$. \% has a higher porosity than $75 \mathrm{wt}$. \%. It implies that the water content of CWTB decreased while the solids content increased. The water content also indicated that the pore size decreased only with the addition of $1 \mathrm{wt}$. \% of binder (after 42 days of curing). It concludes that the binder's reduction does not influence the paste's threshold diameter until the proportion reaches approximately $1 \mathrm{wt}$. \%. In the unconfined compressive strength of cemented tailings backfill, moisture content reduction increases the proportion of solid content in the backfill, increasing its compactness and reducing its porosity.

The results also reveal that the mechanical properties of CWTB are positively related to its microstructure $[14,38]$. The CWTB microstructure performance is affected by the primary phenomenon, namely secondary mineral precipitation and cement hydration [6].

For cemented whole tailings backfill samples, the UCS increases as the binder dosage increases. At $75 \mathrm{wt}$. \% solids content and $5 \mathrm{wt}$. \% binder dry mass dosage, UCS increases, whilst UCS decreases as the solids content and binder dosage decreases. The porosity of the CWTB then becomes significant as a function of the evolution of curing time. Additionally, the increase of cement ratio and the water reduce rate positively affects the cement hydration [16]. However, cemented whole tailings backfill mixtures, as in this study, made from fine aggregates, lose strength faster than those made from coarse aggregates. The volume of voids between the tailings particles to be filled by cement hydration product is very large in paste fill specimens made from fine tailings (higher porosity) than those made from coarser tailings material.

The migration rate of free water leads to the increase of water content in the filling body. As the self-water migration is close to the end, the migration rate also decreases, and the consumption rate of the hydration degree is greater than that of free water, which 
makes the internal acoustic water in the filling body. Due to the decrease of concentration, the free water in the early migration increases, which leads to the extension of the initial acoustic water upper segment [16].

In this stage (Figure 10), due to the water consumption of solidification and evaporation, the water contents in CWTB decreases, and the matrix suction also increases, but the change is relatively slow, which is the stage of slow increase of CWTB strength.

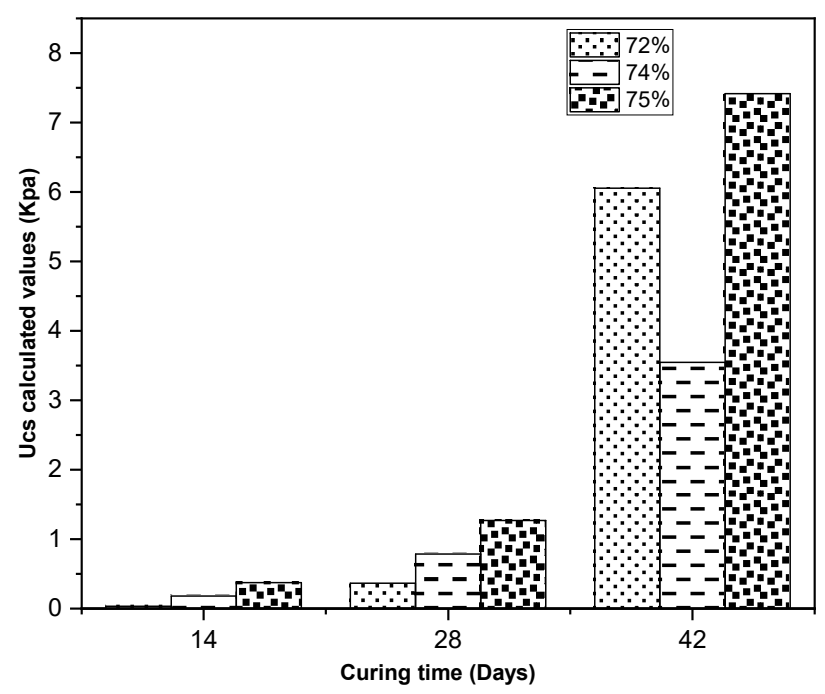

Figure 10. Effect of the solids content of CWTB mixtures prepared with $1 \mathrm{wt}$. \%, 3 wt. \% and $5 \mathrm{wt}$. \% OPC binder on the variation in UCS Calculated with curing time.

Based on the analysis of the correlation mechanism of the paste filling force's multi field performance, the paste solidification is divided into three stages: the increase of moisture content, the rapid consolidation and the slow increase of strength. The reasons for the internal changes of CWTB in these three stages are analyzed.

The influence of porosity on different solids contents of CWTB samples and cement ratio illustrate in Figure 11 were discussed. Figure 11 demonstrates the influence of porosity and cement ratio on the mechanical characteristics of fresh CWTB specimens. On the basis of this graph, it can be obviously discovered that a higher value of UCS results in the increase of fresh CWTB mixtures. That is to say, a higher cement ratio value implies stronger cement hydration process, which generates larger amount of hydration products to raise the viscosity and shear stress of fresh CWTB slurries.

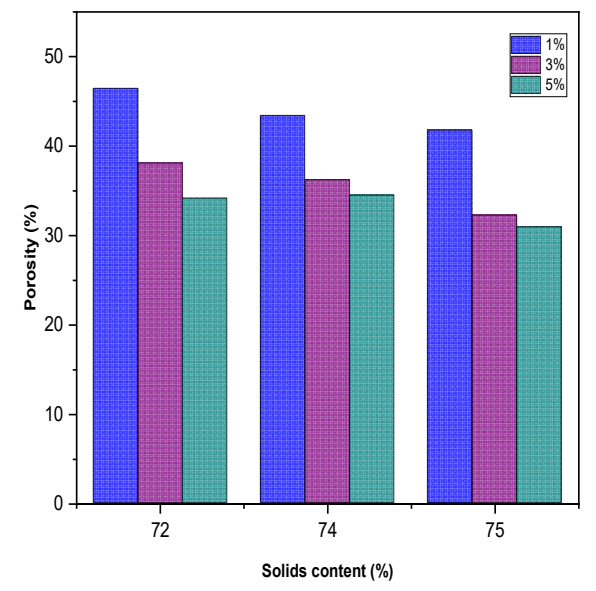

Figure 11. Effect of porosity on different solids contents and cement ratio. 


\section{Conclusions}

In this study, the influence of solid content, curing age and temperature on the preparation of cemented paste backfill CWTB were experimentally evaluated. Notably, a significant change in the slump value was observed with the increase of the solid content designed, which demonstrates the relative influence of the solid concentration on the strength properties of the required CWTB. The slump value obtained in this study according to the different solid concentration demonstrates an ideal slump as compared to the conventional value of the slump.

Regarding the proportion of binder agent, the variation of the fluidity of CWTB mixture showed a high yield stress with the increased of solid concentration. This phenomenon suggested that the addition of ordinary Portland cement in $1 \mathrm{wt}$. \% proved to be very effective in reducing metals' mobility and merging the different CWTB particles. Besides, with the curing age, the strength development of the CWTB mixture at different binder dosage was intensified with the increase of solid concentration. For instance, the strength development was slow in the first 14 days and became more intense within 42 days of curing.

From the performed SEM analysis, we observed significant surrounded hydrated products, confirming the improvement of binding performance between the ordinary Portland cement and the tailings cement matrix.

Additionally, the study also revealed that the tailings particles sizes, particularly the proportions of fine tailings particles $(<20 \mu \mathrm{m})$, significantly affected the porosity of the paste backfill and the pore size distribution within it. The CWTB's overall porosity decreased as the solid concentration increased for a given total mass of cement and tailings for fine tailings.

Therefore, the choice of binder agent depends on the need for specific environmental control and the nature of the tailings selected.

The influence of solids content, binder dosages and water-cement ratio on UCS optimization of CWTBs provides good results on the strength development of the paste backfill samples. Moreover, the curing time significantly increases the UCS of CWTBs at 75 wt. \% solids content.

SEM images confirmed that within 14, 28 and 42 days of curing CWTBs specimens, there were C-S-H gels and ettringite formations, which enhanced the gain strength of CWTBs samples.

Overall, the experiments conducted have raised two main constraints based on the impact of solids content and binder dosage at first, and environmental control specificity according to the curing time. Results to be obtained seem to bring resounding progress on paste backfill process, as far as the topic is concerned. Further studies are needed to confirm the mechanism resistance of the paste backfill in real field conditions.

Author Contributions: A.E.B.T. conceptualized, analyzed the experimental data, initiated the paper, reviewed and editing the paper. S.Y. validated, supervised and acquired funding the paper. L.W. revised and proofread the paper, funded acquisition. All authors have read and agreed to the published version of the manuscript.

Funding: This work was financially supported by the Key Program of National Natural Science Foundation of China (No. 51834001) and the National Science Foundation for Excellent Young Scholars of China (No. 51722401).

Data Availability Statement: We excluded this statement.

Acknowledgments: We would like to acknowledge the courtesy support of the Beijing JCHX Mine Technology Research Institute Co. Ltd. Without its decisive intervention, the experiments could not have been adequately performed, as raw material, samples and equipment have been rendered available under their behalf.

Conflicts of Interest: The authors declare no conflict of interest. 


\section{References}

1. Yin, S.; Shao, Y.; Wu, A.; Wang, H.; Liu, X.; Wang, Y. A systematic review of paste technology in metal mines for cleaner production in China. J. Clean. Prod. 2020, 247, 119590. [CrossRef]

2. Sun, W.; Wang, H.; Hou, K. Control of waste rock-tailings paste backfill for active mining subsidence areas. J. Clean. Prod. 2018, 171, 567-579. [CrossRef]

3. Wu, A.X.; Cheng, H.; Yang, Y.; Zhang, L. Development and challenge of paste technology in China. In Proceedings of the 20th International Seminar on Paste and Thickened Tailings; Wu, A., Jewell, R., Eds.; University of Science and Technology: Beijing, China, 2017; pp. 2-11.

4. Zhao, Y.; Taheri, A.; Karakus, M.; Chen, Z.; Deng, A. Effects of water content, water type and temperature on the rheological behaviour of slag-cement and fly ash-cement paste backfill. Int. J. Min. Sci. Technol. 2020, 30, 271-278. [CrossRef]

5. Qi, C.; Fourie, A. Cemented paste backfill for mineral tailings management: Review and future perspectives. Miner. Eng. 2019, $144,106025$.

6. Yin, S.; Wu, A.; Hu, K.; Wang, Y.; Zhang, Y. The effect of solid components on the rheological and mechanical properties of cemented paste backfill. Miner. Eng. 2012, 35, 61-66. [CrossRef]

7. Yang, S.; Xing, X.; Su, S.; Wang, F. Experimental Study on Rheological Properties and Strength Variation of High Concentration Cemented Unclassified Tailings Backfill. Adv. Mater. Sci. Eng. 2020, 2020, 1-15. [CrossRef]

8. Yang, L.; Qiu, J.; Jiang, H.; Hu, S.; Li, H.; Li, S. Use of Cemented Super-Fine Unclassified Tailings Backfill for Control of Subsidence. Minerals 2017, 7, 216. [CrossRef]

9. Ouattara, D.; Yahia, A.; Mbonimpa, M.; Belem, T. Effects of superplasticizer on rheological properties of cemented paste backfills. Int. J. Miner. Process. 2017, 161, 28-40. [CrossRef]

10. Zhao, Y.; Soltani, A.; Taheri, A.; Karakus, M.; Deng, A. Application of Slag-Cement and Fly Ash for Strength Development in Cemented Paste Backfills. Minerals 2018, 9, 22. [CrossRef]

11. Cheng, H.-Y.; Wu, S.-C.; Zhang, X.-Q.; Wu, A.-X. Effect of particle gradation characteristics on yield stress of cemented paste backfill. Int. J. Miner. Metall. Mater. 2020, 27, 10-17. [CrossRef]

12. Cheng, H.; Wu, S.; Li, H.; Zhang, X. Influence of time and temperature on rheology and flow performance of cemented paste backfill. Constr. Build. Mater. 2020, 231, 117117. [CrossRef]

13. Ansari, W.S.; Chang, J. Influence of fine cement sand paste in preparation of cementitious materials. Constr. Build. Mater. 2020, 230, 116928. [CrossRef]

14. Ouellet, S.; Bussière, B.; Aubertin, M.; Benzaazoua, M. Microstructural evolution of cemented paste backfill: Mercury intrusion porosimetry test results. Cem. Concr. Res. 2007, 37, 1654-1665. [CrossRef]

15. Benzaazoua, M.; Fall, M.; Belem, T. A contribution to understanding the hardening process of cemented pastefill. Miner. Eng. 2004, 17, 141-152. [CrossRef]

16. Li, J.; Yilmaz, E.; Cao, S. Influence of Solid Content, Cement/Tailings Ratio, and Curing Time on Rheology and Strength of Cemented Tailings Backfill. Minerals 2020, 10, 922. [CrossRef]

17. Deb, D.; T, S.; Dey, G.K.; Panchal, S. Paste Backfill Technology: Essential Characteristics and Assessment of its Application for Mill Rejects of Uranium Ores. Trans. Indian Inst. Met. 2016, 70, 487-495. [CrossRef]

18. Cao, S.; Yilmaz, E.; Yin, Z.; Xue, G.; Song, W.; Sun, L. CT scanning of internal crack mechanism and strength behavior of cement-fiber-tailings matrix composites. Cem. Concr. Compos. 2021, 116, 103865. [CrossRef]

19. Cao, S.; Yilmaz, E.; Song, W. Evaluation of Viscosity, Strength and Microstructural Properties of Cemented Tailings Backfill. Minerals 2018, 8, 352. [CrossRef]

20. Standard, A. Standard practice for dry preparation of soil samples for particle size analysis and determination of soil constants. In Annual Book of ASTM (American Society of Testing Material) Standards, 04.08; ASTM International: West Conshohocken, PA, USA, 2007.

21. Yang, L.; Wang, H.; Li, H.; Zhou, X. Effect of High Mixing Intensity on Rheological Properties of Cemented Paste Backfill. Minerals 2019, 9, 240. [CrossRef]

22. ASTM, D. Standard Test Method for Particle-Size Analysis of Soils; ASTM International: West Conshohocken, PA, USA, 2007.

23. Yang, L.; Yilmaz, E.; Li, J.; Liu, H.; Jiang, H. Effect of superplasticizer type and dosage on fluidity and strength behavior of cemented tailings backfill with different solid contents. Constr. Build. Mater. 2018, 187, 290-298. [CrossRef]

24. Clayton, S.; Grice, T.G.; Boger, D.V. Analysis of the slump test for on-site yield stress measurement of mineral suspensions. Int. J. Miner. Process. 2003, 70, 3-21. [CrossRef]

25. Standard, A. Standard test method for slump of hydraulic-cement concrete. In ASTM Annual Book of ASTM Standards; ASTM International: West Conshohocken, PA, USA, 2015.

26. Yilmaz, E.; Belem, T.; Benzaazoua, M. Specimen size effect on strength behavior of cemented paste backfills subjected to different placement conditions. Eng. Geol. 2015, 185, 52-62. [CrossRef]

27. Yilmaz, E.; Belem, T.; Benzaazoua, M. Effects of curing and stress conditions on hydromechanical, geotechnical and geochemical properties of cemented paste backfill. Eng. Geol. 2014, 168, 23-37. [CrossRef]

28. Ouattara, D.; Belem, T.; Mbonimpa, M.; Yahia, A. Effect of superplasticizers on the consistency and unconfined compressive strength of cemented paste backfills. Constr. Build. Mater. 2018, 181, 59-72. [CrossRef] 
29. Panchal, S.; Deb, D.; Sreenivas, T. Variability in rheology of cemented paste backfill with hydration age, binder and superplasticizer dosages. Adv. Powder Technol. 2018, 29, 2211-2220. [CrossRef]

30. Cruz, N.; Forster, J.; Bobicki, E.R. Slurry rheology in mineral processing unit operations: A critical review. Can. J. Chem. Eng. 2019, 97, 2102-2120. [CrossRef]

31. Zhao, M.; Zhang, X.; Zhang, Y. Effect of free water on the flowability of cement paste with chemical or mineral admixtures. Constr. Build. Mater. 2016, 111, 571-579. [CrossRef]

32. Zhao, S.; Fan, J.; Sun, W. Utilization of iron ore tailings as fine aggregate in ultra-high performance concrete. Constr. Build. Mater. 2014, 50, 540-548. [CrossRef]

33. Yilmaz, T.; Ercikdi, B.; Deveci, H. Utilisation of construction and demolition waste as cemented paste backfill material for underground mine openings. J. Environ. Manag. 2018, 222, 250-259. [CrossRef]

34. Wu, A.; Wang, Y.; Wang, H.; Yin, S.; Miao, X. Coupled effects of cement type and water quality on the properties of cemented paste backfill. Int. J. Miner. Process. 2015, 143, 65-71. [CrossRef]

35. Wu, D.; Fall, M.; Cai, S.J. Coupling temperature, cement hydration and rheological behaviour of fresh cemented paste backfill. Miner. Eng. 2013, 42, 76-87. [CrossRef]

36. Cihangir, F.; Ercikdi, B.; Kesimal, A.; Ocak, S.; Akyol, Y. Effect of sodium-silicate activated slag at different silicate modulus on the strength and microstructural properties of full and coarse sulphidic tailings paste backfill. Constr. Build. Mater. 2018, 185, 555-566. [CrossRef]

37. Xue, G.; Yilmaz, E.; Song, W.; Yilmaz, E. Influence of fiber reinforcement on mechanical behavior and microstructural properties of cemented tailings backfill. Constr. Build. Mater. 2019, 213, 275-285. [CrossRef]

38. Yilmaz, E.; Belem, T.; Bussière, B.; Mbonimpa, M.; Benzaazoua, M. Curing time effect on consolidation behaviour of cemented paste backfill containing different cement types and contents. Constr. Build. Mater. 2015, 75, 99-111. [CrossRef] 